\title{
Colorectal cancer morbidity in Poland and Japan in the years 1999-2006 - a comparison
}

\author{
Alicja Klimczak ${ }^{1}$, Marta Miśkiewicz ${ }^{1}$, Michał Mik², Adam Dziki², Mai Utada³, \\ Bogumiła Kempińska-Mirosławska,
}

\author{
1Department of History of Medicine and Pharmacy, Medical University, Lodz, Poland \\ 2Department of General and Colorectal Surgery, Medical University, Lodz, Poland \\ ${ }^{3}$ Department of Mathematical Health Science, Osaka University Graduate School \\ of Medicine, Osaka, Japan \\ ${ }^{4}$ Department History of Medicine, Pharmacy and Military Medicine, Medical University, \\ Lodz, Poland
}

Submitted: 23 February 2012

Accepted: 22 June 2012

Arch Med Sci 2014; 10, 3: 490-497

DOI: $10.5114 /$ aoms.2014.40486

Copyright (C 2014 Termedia \& Banach

\section{Abstract}

Introduction: The frequency of colorectal cancer (CRC) is dependent on sex and age. The illness more often affects men than women, and a considerable increase in morbidity is noted after 65 years of age. The aim of the study was to assess the influence of various risk factors on CRC morbidity, statistical data from countries varied in cultural, socioeconomic and biological terms need to be studied. Poland and Japan can serve as examples of such contrasts.

Material and methods: The basis for the analysis of CRC morbidity was statistical data from Poland and Japan gathered in the period 1999-2006. They were expressed in absolute numbers and were related to the total morbidity, as well as morbidity according to sex and age.

Results: In the years 1999-2006, the total morbidity in Japan was on average 2.3 times higher than in Poland. The value was 2.5 times higher among men and 2.1 times among women when compared to Poland. In both countries morbidity is closely related to age and it reaches a peak between 65 and 74 years of age. Although the change in morbidity over the period was the same for Poland and Japan, there are considerable differences concerning the sex of the patients.

Conclusions: There is a substantial increase in CRC morbidity in both countries, especially among elderly people, which may point to the predominant influence of environmental factors and population aging in both countries. The much higher increase in morbidity among Polish men when compared to Polish women, not observed in the Japanese population, requires further study.

Key words: colorectal cancer, morbidity, statistics, Poland, Japan.

\section{Introduction}

Colorectal cancer (CRC) is one of the most common cancers affecting people in the contemporary world. As observations show, there exist multiple factors which have an impact on the development of the disease. These are environmental, demographic, socioeconomic and biological factors. This cancer occurs more frequently among people over 65 years of age and among men. Poor eating habits, for example low consumption of vegetables, fruit and fiber, foster the emergence of CRC. It is estimated that in highly industrialized countries this factor will contribute to the increase in morbidity by 10 million people over the next 20 years [1, 2].

\author{
Corresponding author: \\ Alicja Klimczak \\ Department of History \\ of Medicine and Pharmacy \\ 2 Muszyńskiego St \\ 90-151 Lodz, Poland \\ Phone/fax +48 426779287 \\ E-mail: ala_klimczak@o2.pl
}


Disparities are observed in the morbidity of countries from different continents. It may be gathered from the Globocan 2000 epidemiological data that the occurrence of malignant tumors (colorectal cancer, cancers of the prostate, oral cavity, esophagus and cervix) is much more frequent in developed countries than in developing countries (in which cancers of the stomach, liver, breast and pancreas prevail) [3]. Studies have shown that CRC morbidity is also related to population aging, which consists in the increase of the ratio between the number of old people and the total population. It is one of the basic problems of modern times. This issue appeared in Poland for the first time at the turn of the 1950s and 1960s. In the period 19502003 , the percentage of people over 64 in the total population increased from $5.3 \%$ to $13.0 \%$ [4]. Population aging in Japan, described as the oldest country in the world, is at an alarming level. The percentage of elderly men is approximately $20 \%$, while the percentage of women is about $25.4 \%$. In total, almost 23 million Japanese people $(22.8 \%$ of the population) have already turned 65 years of age. The number has increased by 800,000 since last year [5]. As the data concerning population according to sex and age groups demonstrate, the populations of both Poland and Japan are aging, but the Polish population is younger. In the years 19992006 the number of people under 34 years of age decreased from $50.0 \%$ to $47.6 \%$ in Poland, whereas in Japan it decreased from $42.5 \%$ to $38.4 \%$. At the same time, the percentage of people over 74 years of age increased; in Poland it changed from $4.2 \%$ to $5.7 \%$ and in Japan it increased from $6.7 \%$ to $9.5 \%$. In general, the percentage of people over 55 is higher in Japan than in Poland. In the year 1999 , the value was $29.8 \%$ in Japan and $20.7 \%$ in Poland, while in the year 2006 it was $35.7 \%$ and $24.0 \%$, respectively $[6,7]$.

Malignant tumors had been the main cause of mortality in Japan for many years. The government decided to regard tumors as a priority and consequently the administrative policy of this country focused on their detailed control. In 1984 a cancer control program began, under the name of "Comprehensive 10-Year Strategy for Cancer Control", which aimed at explaining the etiopathogenesis of cancer. The program turned out to be successful in discovering oncogenes and tumor suppressor genes. In 1994 another program appeared, with the name "New 10-Year Strategy to Overcome Cancer", which in addition to expanding the study scope contained explanations concerning the character of CRC. The results were used later in the prevention and treatment of the disease. The third strategy was introduced in 2004 and will last until 2013. Currently, at 2-year intervals, the Foundation for Cancer Research "Statistics of Cancer in Japan" pub- lishes statistics concerning morbidity and mortality for malignant tumors in Japan [8].

As may be concluded from the statistical data, CRC morbidity has been increasing in Japan for many years and CRC is estimated to have become the most frequent tumor by the year 2010, both among men and among women [9]. Colorectal cancer is now the second - after stomach cancer most frequent tumor [10]. In Poland the epidemiological situation of this disease is also alarming, because since the year 1999 an increase in the morbidity rates of both sexes has been observed, expressed in absolute numbers [11].

The aim of this study was to compare CRC morbidity in total and according to the sex and age of the patients, in Poland and in Japan in the years 1999-2006. Morbidity values were expressed in absolute numbers and as a rate per 100,000 persons.

\section{Material and methods}

The subject of the analysis was the epidemiological data concerning CRC morbidity in the years 1999-2006, but it was only morbidity classified with such ICD-10 codes as C18, C19, C20, C21. The Polish data came from the National Cancer Registry, while the Japanese data were obtained from the Center for Cancer Control and Information Services, National Cancer Center, Japan. Statistical data on morbidity and mortality of CRC for Japan come from the national cancer registry system. The national cancer registry system is not covered by any law, so the most authoritative data are the estimated data. The reported nationwide incidence data consist of the estimated number based on some prefecture-wide population-based cancer registries in Japan. It should be noted that the Japanese incidence data may not be real incidence.

The analysis included the total morbidity, as well as morbidity by sex and age groups. The basis for the analysis was the division into 6 age groups (below 34 years of age, between 35 and 44, 45-54, 55-64, 65-74 and over 74 years of age). The reason for such division is the fact that in the age group below 34 years of age CRC morbidity values in both countries are at a low level, i.e. below 1\% (approximately $0.6 \%$ in Japan and $0.8 \%$ in Poland). By contrast, in the age group 35-44 the rate increases as much as 5 times. In the decades that follow, the increase amounts to 1.5-3.5 in comparison with the previous decade. The analyzed data were expressed in absolute numbers and as incidence rates (overall, by sex and in age groups) per 100,000 population. The demographic data concerning the size of the Polish population were obtained from the National Cancer Registry and Central Statistical Office, while the Japanese data were gathered from the Statistical Survey Department, Statistics Bureau, 
and Ministry of Internal Affairs and Communications [7].

\section{Statistical analysis}

To evaluate data despcriptive statistics were used (mean, rate). To analyze the correlations between the morbidity rate and population structure in the years 1999-2006 Pearson's correlation coefficient test was used. The significance level $p$-value $<0.05$.

\section{Results}

Over the years 1999-2002, CRC morbidity in Japan increased for both sexes, reaching a total of 105,195 cases in 2002 (61,970 men and 43,225 women). In 2003, this number decreased to 99,770 (57,610 men and 42,160 women). Then, in the years 2005-2006 the number of cases began to rise again, reaching the value of 107,815 in 2006 (62,648 men and 45,167 women). On the other hand, CRC morbidity (C18-C21) in Poland was on the increase over the years 1999-2006. The value ranged from 11,644 cases (6,075 men and 5,569 women) in the year 1999 , to 13,987 (7,614 men and 6,373 women) in the year 2005 and 13,898 (7,664 men and 6,234 women) in 2006. Colorectal cancer morbidity expressed in absolute numbers, both in Poland and in Japan, was higher among men than among women. In Japan the value of men's proportional morbidity was $0.57-$ 0.59 , while in Poland it was $0.52-0.55$. For women the values were respectively $0.41-0.43$ and 0.45 0.48 . The change in CRC morbidity over the years 1999-2006 in Japan and in Poland in total was the same and equaled $19.4 \%$. The analysis of the data according to sex, in turn, leads to the observation that the men's morbidity was $18.9 \%$ in Japan and $26.2 \%$ in Poland, while the women's morbidity was $20.1 \%$ in Japan and $11.9 \%$ in Poland.

Colorectal cancer morbidity in Japan in the years 1999-2006 was rising together with age and in the age group 45-54 it equaled 9,089 cases in 1999, while in the age group 65-74 the number was as high as 30,455. In the year 2006 the total morbidity in the age group 45-54 was lower than in 1999 and was 7,901, whereas in the age group 65-74 the number of cases increased considerably when compared to the year 1999 and was 33,586.

In Poland the morbidity rate in different age groups was on the increase and in 1999 it was 1,308 cases for the age group 45-54, while for the group 65-74 it was 4,198. In the year 2006 the values were higher and stood at 1,543 for the age group 45-54 and 4,482 for the age group 65-74. The changes in CRC morbidity (C18-C21) were the same in Poland and Japan and equaled $19.4 \%$.

Colorectal cancer morbidity among men (C18C21) in Japan in the years 1999-2006 was growing with age and in the year 1999 it ranged between
5,597 (for the age group 45-54) and 19,455 (for the age group 65-74). In the year 2006 the morbidity rate among men was 4,690 for the age group 4554, and 21,352 for the group 65-74. In Poland, in turn, CRC morbidity among men (C18-C21) was also growing with age and in the year 1999 it stood at 697 for the age group 45-54 and 2,336 for the age group 65-74. The situation was analogous in 2006 when the numbers equaled respectively 875 and 2,659. The change in CRC morbidity (C18-C21) among men in Japan ranged from 19.1\% (below 34 years of age) to $55.1 \%$ (over 74 years of age). In total, morbidity for men in Japan amounted to $18.9 \%$. In Poland these changes ranged from $21.2 \%$ (below 34 years of age) to $50.05 \%$ (over 74 years of age). The total CRC morbidity among men in Japan increased by $26.2 \%$.

Colorectal cancer morbidity among women (C18C21) in Japan in the years 1999-2006 was growing with age and in the year 1999 it ranged between 3,492 (for the age group 45-54) and 11,000 (for the age group 65-74). In the year 2006 the morbidity rate among women was 3,211 for the age group 45-54, and 12,234 for the age group 65-74. In Poland CRC morbidity among women (C18-C21) was growing with age and in the year 1999 it totaled 611 for the age group 45-54 and 1,862 for the age group 65-74. In 2006, in turn, the numbers respectively stood at 668 and 1,823 . The changes in morbidity by age groups in Japan equaled $11.4 \%$ for the age group below 34 , and $42.7 \%$ for the group over 74 years of age. In Poland the values were $23.7 \%$ and $23.1 \%$, respectively. In total, the change in morbidity was $20.1 \%$ for Japan and $11.9 \%$ for Poland (Figure 1 ).

The CRC morbidity rate per 100,000 population (C18-C21) in Japan fluctuated and assumed the following values: 71.3 in the year 1999, then 82.5 in 2002, after which it grew to 84.4 in 2006. The values for men were $84.9,99.5$, and 100.5 , respectively. For women, the rates were 58.2 in 1999, 66.3 in 2002 and 69.0 in 2006 (Figure 2).

The CRC morbidity rate (C18-C21) in Poland was 30.4 in the year 1999, after which it increased with small fluctuations and reached the value of 36.5 in 2006. Among men the value increased from 32.8 in 1999 to 41.6 in 2006. A similar growth was shown by the morbidity rate among women. It was 28.2 in 1999 and 32.3 in 2005, after which it decreased slightly to reach the value of 31.6 (Figure 3).

The CRC morbidity rate was growing with age and in 1999 it was 47.1 in the age group 45-54, while it was 240.0 in the age group 54-65. In 2006 the values were 49.0 and 232.6, respectively. Generally, there was an increase in the morbidity rate by $18.4 \%$ (Figure 4 ).

The CRC morbidity rate was growing with age and it exhibited considerable differences. In the year 1999 in the age group 45-54 it was 24.5, while in 


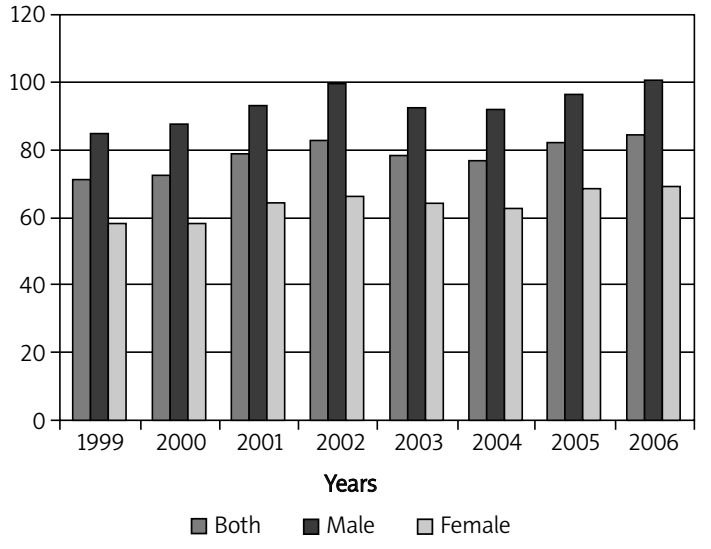

Figure 1. Colorectal cancer morbidity rate (C18-C21) by sex in Japan in the years 1999-2006

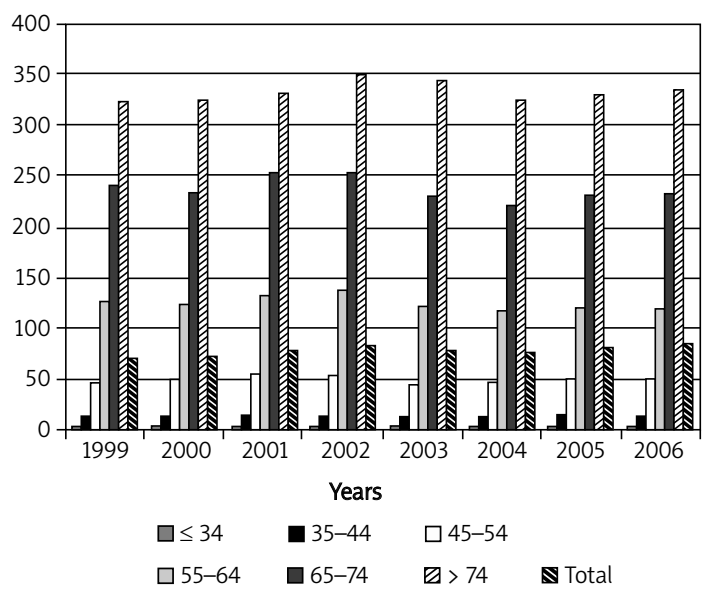

Figure 3. Colorectal cancer morbidity rate (C18-C21) by age groups in Japan in the years 1999-2006

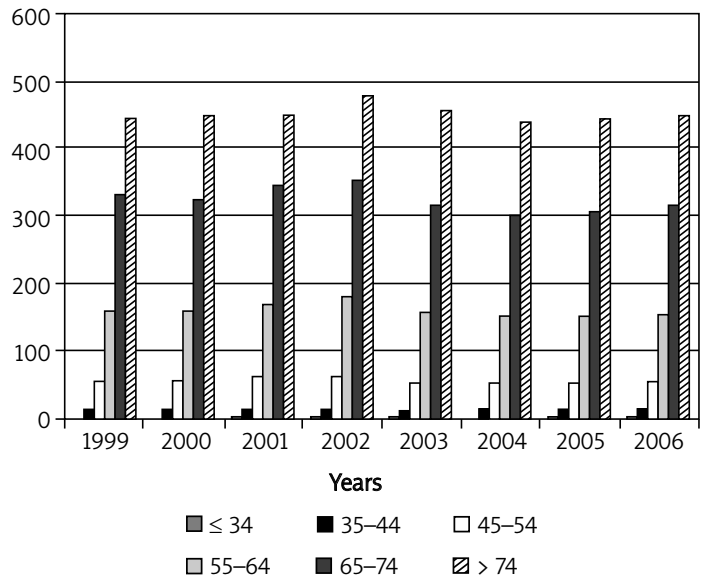

Figure 5. Colorectal cancer morbidity rate (C18-C21) among men by age groups in Japan in the years 1999-2006

the age group 65-74 it was 140.5. In 2006 the values increased and stood at 25.9 in the age group $45-54$, and at 153.9 in the age group $65-74$. Generally there was a rise in the morbidity rate by $21.0 \%$ (Figure 5).

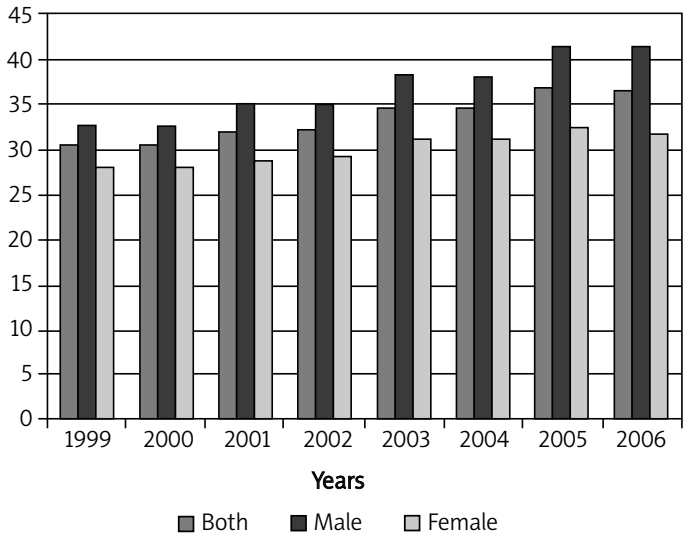

Figure 2. Colorectal cancer morbidity rate (C18-C21) by sex in Poland in the years 1999-2006

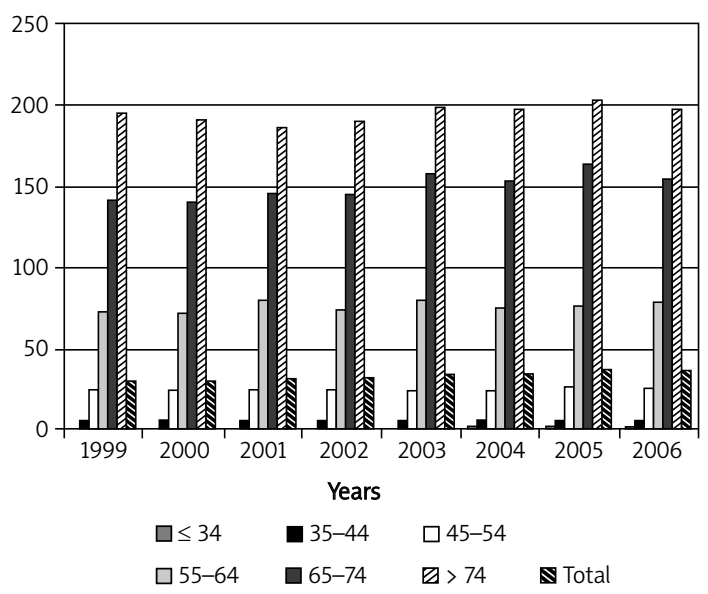

Figure 4. Colorectal cancer morbidity rate (C18-C21) by age groups in Poland in the years 1999-2006

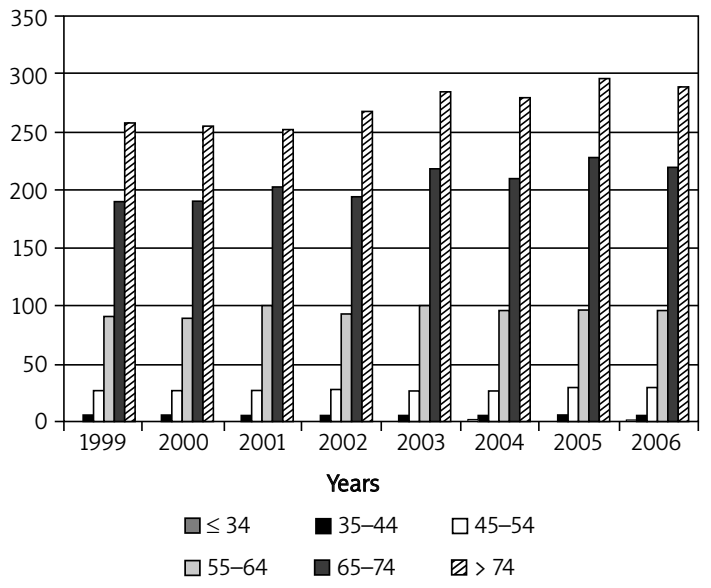

Figure 6. Colorectal cancer morbidity rate (C18-C21) among men by age groups in Poland in the years 1999-2006

The CRC morbidity rate (C18-C21) among men in Japan started to grow considerably among the age group 45-54, in which it amounted to 58.1 in the year 1999, while in the age group 65-74 it was 332.6. In the year 2006 the numbers were 58.2 and 315.1, 


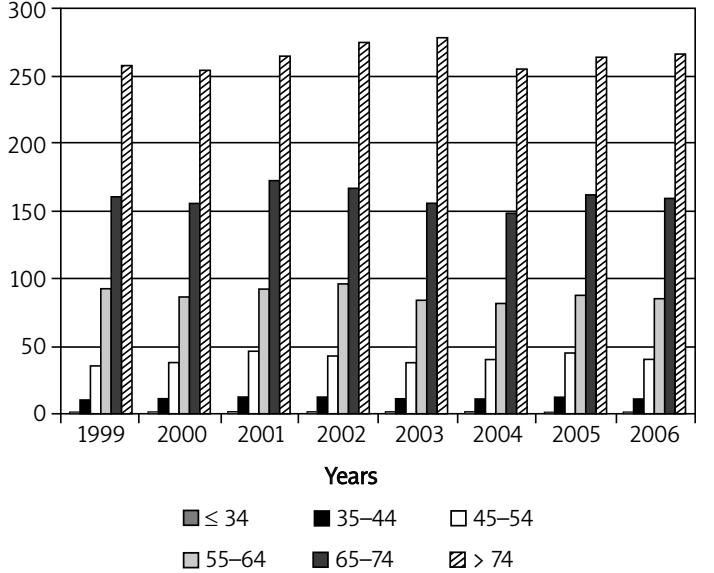

Figure 7. Colorectal cancer morbidity rate (C18-C21) among women by age groups in Japan in the years 1999-2006

respectively. The increase in the morbidity rate over the years 1999-2006 was $18.3 \%$ (Figure 6).

The CRC morbidity rate (C18-C21) among men in Poland in the period 1999-2006 increased. In 1999 it was 26.7 in the age group 45-54; it grew rapidly in the age group $65-74$, reaching the value of 190.8. In 2006 the trend was similar: in the age group 45-54 the rate was 30.0, while in the age group 65-74 it was 219.9. The change of the morbidity rate was $28.6 \%$ (Figure 7 ).

The CRC morbidity rate (C18-C21) among women in Japan increased and was dependent on age. In 1999 in the age group 45-54 it was 36.1, while in the group 65-74 it was 160.9. In 2006 the rate equaled 39.9 and 159.7, respectively. The increase of the morbidity rate was $18.7 \%$ (Figure 8 ).

The CRC morbidity rate (C18-C21) among women in Poland increased in the period 1999-2006. In 1999 in the age group 45-54 the morbidity rate was 22.4 , while in the age group 65-74 it was 105.5. In 2006 the rate equaled 22.0 and 107.1 , respectively. The increase of the morbidity rate was $12.9 \%$ (Table I).

In the years 1999-2006 in Japan there was dependence between the change in the CRC morbidity rate in total and between the change in the population structure. The increase in the percentage of people aged 55-64, 65-74 and over 74 years of age was associated with an increase in morbidity and the highest association occurred in the age group 65-74 (correlation coefficient 0.87). In Poland,

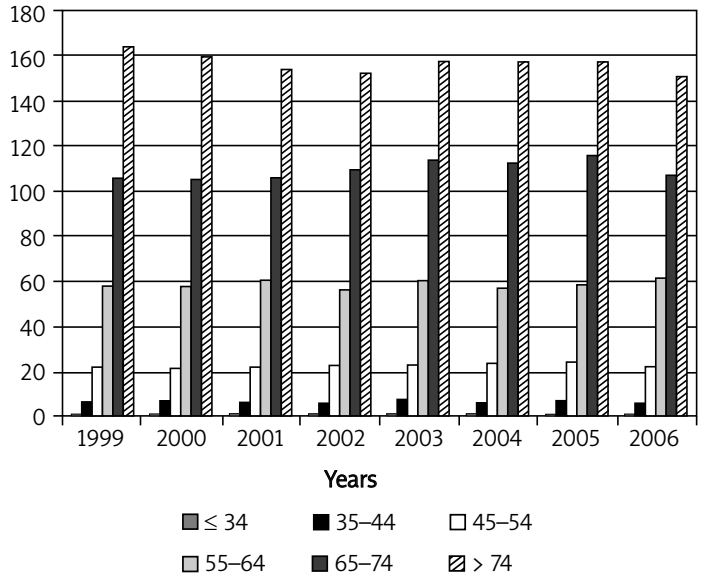

Figure 8. Colorectal cancer morbidity rate (C18-C21) among women by age groups in Poland in the years 1999-2006

a strong positive correlation occurred for the age group 55-64 and in the group over 74 (coefficients were at the level of 0.94). For the age group 65-74, the value was negative (coefficient -0.19). In the period 1999-2006 in Poland, even though the percentage of people aged 65-74 remained roughly at the level of $7.7 \%$, there occurred an increase in the CRC morbidity rate in this group, both in the total population and with the division according to sex.

\section{Discussion}

Colorectal cancer constitutes one of the leading causes of cancer in general in developed countries (e.g. in the USA it is ranked as the third main cause). As far as the frequency of the occurrence of CRC is concerned, epidemiological studies point to an upward trend. Nevertheless, another aspect of the issue which is worth noting is the considerable differences in the morbidity rates (expressed as the number of cases per 100,000 inhabitants) between individual countries. Study and analysis of these differences are essential in the research on the risk factors of CRC morbidity, involving not only age or sex factors, but also dietary habits revealing cultural differences or genetic distinctions of a given population. Poland and Japan are examples of two countries which differ in demographic, environmental and dietary factors.

As may be concluded from the study, there are also substantial differences in CRC morbidity (over-

Table I. Correlation coefficients between the change in the morbidity rate in total and the change in the population structure of three age groups, 55-64, 65-74 and over 74, in the years 1999-2006. For each values of correlation coefficient $p$-value 0.05

\begin{tabular}{|lcccccccccc|}
\hline Country & \multicolumn{3}{c}{ Both } & \multicolumn{3}{c}{ Male } & \multicolumn{3}{c|}{ Female } \\
\cline { 2 - 22 } & $55-64$ & $65-74$ & $>74$ & $55-64$ & $65-74$ & $>74$ & $55-64$ & $65-74$ & $>74$ \\
\hline Japan & 0.58 & 0.87 & 0.84 & 0.52 & 0.82 & 0.75 & 0.63 & 0.89 & 0.84 \\
\hline Poland & 0.93 & -0.19 & 0.94 & 0.94 & 0.30 & 0.97 & 0.88 & -0.56 & 0.95 \\
\hline
\end{tabular}


all, as well as by age and sex) expressed as the number of cases per 100,000 inhabitants. In the years 1999-2006 the morbidity rate of the general population in Japan was on average 2.3 times higher than in Poland, with a 2.5 times higher rate among men and 2.1 higher among women. Interesting distinctions in the morbidity rates of Poland and Japan can be observed in different age groups. In the years 1999-2006 in Japan, despite the increase in the morbidity in the total population, there was a decrease in the morbidity rate of the age groups 55-64 and 65-74 for the general population as well as for individual sexes. In Poland, on the other hand, the morbidity rate was increasing for the same age groups. In both countries the morbidity rate increased among younger people, i.e. in the age group 35-44, both for the general population and for men. The tendency was different for women: in Poland the rate remained at a similar level, whereas in Japan it showed an upward trend. The CRC morbidity rate was growing for the age group over 74 years of age in Japan, while in Poland it remained at a stable level. The increasing morbidity rate among younger age groups in Japan may be related to the enhanced detection of the disease at an early stage, which was a result of prevention programs. There was a considerable difference between the morbidity trends for women in the age group 65-74 in Poland (correlation coefficient between the change in the overall morbidity rate and the change in the population structure of women - 0.56) and Japan. This difference may point to a substantial influence of factors other than population aging on CRC morbidity.

In Japan, the number of CRC operations in elderly people increases together with the population aging. The choice of the appropriate method of treatment is then crucial and depends on the patient's condition. Past experience demonstrates that $75 \%$ of older patients have had complications before the surgery. Circulatory and respiratory problems appeared more frequently after the surgery. However, appropriate treatment and preparation give good results when it comes to postoperative and 5-year survival. Chemotherapeutic treatment of the elderly can also be used as long as the patient's vital signs are assessed positively [12].

In order to counteract the negative trends, a prevention screening program was introduced in 1992 in Japan. The program aimed at early detection of CRC and it was addressed at people over 40 years of age [13]. It consisted of colonoscopy and sigmoidoscopy, together with a contrast examination with the use of barium suspension. Over 6 million people were examined in the course of the program in 2002 (which constituted 17\% of the population eligible for the study). From this group, CRC was diagnosed in slightly more than 9,700 people
(0.16\%). Unfortunately, as in Poland, the problem is still the low participation of people in preventive screening programs. According to the study coordinators, it is the main obstacle in the process of diminishing CRC morbidity [13].

Among the factors contributing to the frequency of CRC morbidity, there are such aspects as dietary, genetic, hormonal and other factors (e.g. drugs, medicines), but also obesity, smoking and excessive consumption of alcohol [14]. Smoking in Japan is very common ( $43 \%$ of men and $12 \%$ of women were smokers in the year 2004) [15].

It is also known that the risk of CRC increases with age, even though aging and carcinogenesis are two different processes related to e.g. an accumulation of DNA damage and abnormal proteins. Thanks to the development of molecular biology, people are familiar with such issues as accumulation of genetic and epigenetic changes in both aging and carcinogenesis. There exists a process of DNA methylation, which often participates in the control of the gene functions during the development of cancer. The percentage of CRC cases with hypermethylation of the $\mathrm{hMLH} 1$ promoter increases with age, accounting for $25-30 \%$ of all colorectal cancers. Nevertheless, the phenomenon described above may only be responsible for approximately one-third of cancers among the elderly [16].

Western literature emphasizes the positive protective role of consuming sufficient amount of fruit and vegetables. However, the study conducted among Japanese people in the years 19901999 did not show any correlation between this diet and CRC morbidity. Researchers suggest that low consumption of fruit and vegetables was not the main cause of increased frequency of CRC morbidity in Japan in the years 1950-2000 [17]. In the period 1975-2005 in Japan the intake of yellow and green vegetables increased almost 2 times, whereas the consumption of fruit and soy products decreased by approximately $36 \%$ and $9 \%$ per capita, respectively [18]. From the beginning of the 1990s in Poland there was a decline in the consumption of vegetables and a growth in the intake of fruit, with the result that at the end of the 1990s the fruit consumption increased almost two times when compared to the beginning of this period [19].

Furthermore, genetic factors may affect morbidity. Some studies point to a statistically significant relation between the increased frequency of CRC in the Japanese population and the changes on the chromosome 8q24 at locus rs6983267. However, this risk factor is independent of other factors, such as smoking, age or sex [20].

What is more, it has been demonstrated that not only epithelial but also stromal genetic instability can be partly responsible for the occurrence 
of colorectal cancer. Studies have shown that genomic instability of MSI and LOH in noncancerous colonic mucosa, and especially epithelial and stromal $\mathrm{LOH}$, occurs relatively early in adults. It points to changes related to aging which may increase the risk of colorectal cancer, especially among men [21].

The majority of colorectal cancers develop from adenomas and are related to aging. Lieberman's studies have shown that the occurrence of hyperplastic polyps in men aged $50-75$ accounts for $12.5 \%$ [22].

The observed differences in CRC morbidity between men and women (with the predominance of males, both in Western countries and Japan) indicate that hormonal factors may also be essential. Nevertheless, the potentially protective function of estrogens has not been fully proved [23]. An argument in favor of the protective influence of estrogens could be the fact that there are differences in the morbidity rates between men and women, taking age into account. As studies have shown, CRC occurs more frequently among women over 55 years old than among men, but rectal cancer appears with equal frequency among both sexes and becomes almost twice as common among men over 65 years of age [24]. Our research revealed that in the age group below 54 years of age CRC occurs more frequently among men than among women, both in Poland and in Japan.

Japanese researchers have undertaken an analysis of the relation between the intake of isoflavonoids (which are so-called phytoestrogens) in the diet and the risk of developing CRC (glandular form). The studies showed that decreased consumption of isoflavonoids in the diet was accompanied by an increase in CRC morbidity [23]. This relation was more salient among women than men. The beneficial activity of phytoestrogens may result from the fact that they diminish the proliferation of tumor cells. What is more, they perform antioxidant functions, as well as inhibiting cell cycle progression and angiogenesis in endothelial cells.

The research of the Nurses Health Study has shown that women who use contraceptives for a period of at least 8 years [25] suffer from CRC much less frequently, which was also proved by the study of Fernandez et al. [26]. The risk of the occurrence of colon cancer was diminished by about $18 \%$ among women using oral contraceptives. Similarly, estrogens are known to hinder the development of CRC cells under in vitro conditions, and they decrease the concentration of IGF-1. The IGF-1 is a strong mitogenic compound which influences the development of this cancer, as has been pointed out in the article of Ginovannucci et al. [27].

In conclusion, colorectal cancer is a serious and increasing health problem, both in Poland and in Japan. There is a considerable increase in CRC mor- bidity in both countries, especially among elderly people, which may point to the prevailing influence of environmental factors on the development of this tumor. Population aging in Poland and Japan has the effect that total morbidity in both countries has an upward trend after 65 years of age. The much higher increase in morbidity among Polish men when compared to Polish women, which was not observed in the Japanese population, requires further study. Furthermore, epidemiological studies demonstrate a substantial difference in the morbidity rates between Japanese and Polish women, the former group having the higher rate. This situation might have been caused by a range of factors, for example contraception, and for this reason this problem requires further study.

\section{References}

1. Cancer: diet and physical activity's impact-WHO. www. who.int/dietphysicalactivity/publications/facts/cancer/en.

2. Papas AM. Chemoprevention for gynecological cancer high risk patients. EAGC 2nd International Congress on Gynecological Malignancies 2004; 24-5.

3. Korniluk J, Wcisło G, Murzyński P. Colorectal cancer epidemiology. Contem Oncol (Poznan) 2006; 10: 136.

4. Długosz Z, Kurek S. Starzenie się ludności w Polsce na tle regionów Unii Europejskiej [Polish]. Konspekt 2005; 4: 96-8.

5. Available at: http://news.money.pl/artykul/japonia;spoleczenstwo;starzeje;sie;w;dramatycznym;tempie,235,0,536299. html (January, 2012)

6. http://www.stat.gov.pl/bdl/app/dane_podgrup.display? p_id $=152741 \&$ \&_token $=0.3346702600829303$

7. Statistics Bureau. http://www.stat.go.jp/english/data/ chouki/02.htm.

8. Cancer statistics in Japan 2007. www.ganjoho.jp/public/ statistics/backnumber/2007_en.html.

9. Ohno Y, Nakamura K, Murata K, et al. Estimation of cancer incidence in Japan in the Future.In: Cancer statistics Morbidity/morbidity/prognosis. Tokyo: Shinohara Publishing Ltd 2004; 201-18.

10. Shiroiwa T, Fukuda T, Tsutani K. Health utility scores of colorectal cancer based on societal preference in Japan. Qual Life Res 2009; 18: 1095-103.

11. Klimczak A, Kempińska-Mirosławska B, Mik M, Dziki A. The incidence of colorectal cancer in Poland in 1999-2008. Arch Med Sci 2011; 7: 673-8.

12. Takahashi K, Matsumoto H, Yamaguchi T, et al. Surgery for colorectal cancer in elderly patients. Gan TO Kagaku Ryoho 2010; 37: 2823-8.

13. Saito H. Colorectal cancer screening using immunochemical faecal occult blood testing in Japan. J Med Screen 2006; 13 (Suppl. 1): S6-7.

14. Omata F, Bron WR, Tokuda Y, et al. Modifiable risk factors for colorectal neoplasms and hyperplastic polyps. Intern Med 2009; 48: 123-8.

15. www.health-net.or.jp/tobacco/product/pd 100000.html.

16. Arai T, Kasahara I, Sawabe M, Honma N, Aida J, Tabulo K. Role of methylation of the hMLH1 gene promoter in the development of gastric and colorectal carcinoma in the elderly. Geriatr Gerontol Int 2010; 10 (Suppl. 1): S207-12.

17. Tsubono Y, Otani T, Kobayashi M, Yamamoto S, Sobue T, Tsugane S. No association between fruit or vegetable 
consumption and the risk of colorectal cancer in Japan. Br J Cancer 2005; 92: 1782-4.

18. Analysis of Annual Survey Results, report prepared by Ministry of Health, Labor and Welfare - www.mhlw.go.jp/ english/index.html.

19. http://www.ppr.pl/artykul-zachowania-konsumpcyjne-iwzorce-spozycia-2920-dzial-19.php

20. Matsuo K, Suzuki T, Ito $\mathrm{H}$, et al. Association between an $8 q 24$ locus and the risk of colorectal cancer in Japanese. BMC Cancer 2009; 9: 379.

21. Umeto H, Yoshida T, Araki K, Yagishita H, Mikami T, Okayasu I. Appearance of epithelial and stromal genomic instability in background corolectal mucosa of sporadic colorectal cancer patients: relation to age and gender. Gastroenterology 2009; 44: 1036-45.

22. Lieberman DA, Prindiville S, Weiss DG, Willett W. Risk factors for advanced colonic neoplasia and hyperplastic polyps in asymptomatic individuals. JAMA 2003; 290: 2959-67.

23. Akhter M, Iwasaki M, Yamaji T, Sasazuki S, Tsugane S. Dietary isoflavone and the risk of colorectal adenoma: a case-control study in Japan. Br J Cancer 2009; 100: 1812-6.

24. Singh S, Sheppard M C, Langman MJS. Sex differences in the incidence of colorectal cancer: an exploration of oestrogen and progesterone receptors. Gut 1993; 34: 611-5.

25. Marchbanks PA, McDonald JA, Wilson HG, et al. The NICHD Women's Contraceptive and Reproductive Experiences Study: methods and operational results. Ann Epidemiol 2002; 12: 213-21.

26. Fernandez E, La Vecchia C, Balducci A, et al. Oral contraceptives and colorectal cancer risk: a meta-analysis. Br J Cancer 2001; 84: 722-7.

27. Ginovannucci E, Pollak MN, Platz EA, et al. A prospective study of plasma insulin-like growth factor- 1 and binding protein-3 and risk of colorectal neoplasia in women. Cancer Epidemiol Biomarkers Prev 2000; 6: 345-9. 